\title{
Effect of apoptosis and response of extracellular matrix proteins after chemotherapy application on human breast cancer cell spheroids
}

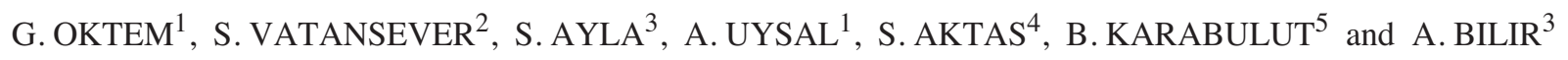 \\ ${ }^{1}$ Department of Histology and Embryology, Ege University School of Medicine, TR-35100 Izmir; ${ }^{2}$ Department of Histology \\ and Embryology, Celal Bayar University School of Medicine, TR-45030 Manisa; ${ }^{3}$ Department of Histology and Embryology, \\ Istanbul University School of Medicine, Istanbul; ${ }^{4}$ Department of Pathology, Dr Behcet Uz Teaching Hospital for Children; \\ ${ }^{5}$ Department of Medical Oncology, Ege University School of Medicine, TR-35100 Izmir, Turkey
}

Received February 24, 2005; Accepted May 12, 2005

\begin{abstract}
Multicellular Tumor Spheroid (MTS) represents a three-dimentional structural form of tumors in laboratory conditions, and it has the characteristics of avascular micrometastases or intervascular spaces of big tumors. Recent studies indicate that extracellular matrix (ECM) proteins play a critical role in tumor metastasis, therefore normal and cancer cells require an ECM for survival, proliferation and differentiation. Doxorubicin and Docetaxel are widely used in the therapy of breast cancer, as well as in in vivo and in vitro studies. In this study, we examined the effect of apoptosis and proliferation of cells on the human breast cancer cell line, MCF-7, by using p53, bcl-2 and Ki67 gene expression, and the tendency to metastasis with extracellular matrix proteins, laminin and type IV collagen after chemotherapy in the spheroid model. The apoptotic cell death in situ was detected by TUNEL method. TUNEL-positive cells and positive immunoreactivities of laminin, type IV collagen, p53 and, bcl-2 were detected in the control group. There was no laminin and type IV collagen immunoreactivities in spheroids of drug groups. While TUNEL-positive cells and p53 immunoreactivity were detected in Docetaxel, Doxorubicin and Docetaxel/Doxorubicin groups, p53 immunoreactivity was not observed in the Docetaxel group. There was no bcl-2 immunoreactivity in either drug group. In addition, we did not detect Ki67 immunoreactivity in both control and drug treatment groups. However, the absence of Ki67 protein in MCF-7 breast multicellular tumor spheroids is possibly related to the cells in $\mathrm{G} 0$ or $\mathrm{S}$ phase. These chemotherapeutic
\end{abstract}

Correspondence to: Dr Gülperi Öktem, Department of Histology and Embryology, Ege University School of Medicine, TR-35100 Izmir, Turkey

E-mail: goktem@med.ege.edu.tr goktem@hotmail.com

Key words: spheroid, chemotherapy, apoptosis, ECM proteins agents may affect the presence of ECM proteins in this in vitro model of micrometastasis of spheroids. These findings suggest that the possible mechanism of cell death in Doxorubicin and Docetaxel/Doxorubicin treatment groups is related to apoptosis through the p53 pathway. However, we considered the possiblity that there is another control mechanism for the Docetaxel group.

\section{Introduction}

Breast cancer is known be one of the most common types of cancer. Over half a million women develop breast cancer every year and breast cancer accounts for almost $20 \%$ of all malignancies world-wide (1). Many patients with metastatic breast cancer, however, develop recurrences after an initial response to chemotherapy. More than three quarters of patients with metastatic breast cancer die within 5 years of diagnosis (2). Discovery of new therapeutic regimens for such patients is, therefore, most urgently required. The in vitro investigations made for the diagnosis and therapy of breast cancer may lead a way for further in vivo studies. Multicellular Tumor Spheroid Model (MTS) is a model for in vitro monolayer cell cultures and solid tumors (3). Spheroid cultures mimic both the threedimentional organization and differentiated function of intact tissue to a much greater extent than do cell monolayers (4). Another important advantage of 3-D cultures is that they have a morphological shape of which every detail can be observed easily. This morphological shape may give us the opportunity to observe diffusing macromolecules and analyze the environmental conditions.

The normal function of the mammary gland is dependent on the action of hormones and growth factors, as well as extracellular matrix $(\mathrm{ECM})$ proteins $(5,6)$. The laminin, a large family of heterotrimeric glyco-proteins, are major components of basement membranes (7) and mediate the attachment of epithelial and neoplastic cells to type IV collagen (8-10). Interactions with the basement membrane are crucial for cancer progression, in that breaching of the basement membrane by cancer cells is a prerequisite for malignant tumors (11). Besides, some tumors may secrete laminin which may interact with type IV collagen that takes place in the structure of the 
basement membrane. Terranova et al showed that the MCF-7 cells secrete laminin which is adhesive for basement membrane in a study in 1983 (12). Moreover, lower concentrations of all the ECM components induced the migration and invasion of several cell lines. However, in the case of the SNB19 cell line, laminin inhibited both migration and invasion in a concentration-dependent manner (13).

The mechanism by which tumor cells become invasive and eventually metastatic is a crucial question in cancer biology and medicine $(14,15)$. The metastatic process requires that a cell acquire a motile phenotype to penetrate tissue and reach the vasculature and lymphatics. Another step that is necessary for cancer cells to metastase is their attachment to the basement membrane. Multicellular spheroids are an in vitro model of micrometastasis whose adhesive abilities have not been elucidated (16). The ECM either in normal or malignant tissue may play an important role in the progress of metastasis. Recent studies indicate that normal and cancer cells require an ECM for survival, proliferation and differentiation $(17,18)$.

Apoptosis is a physiologically programmed mechanism of cell death and it is regulated by several additional genes, which potentate (p53, Bax, c-myc) or inhibit (Bcl-2, Bcl xL, sentrin) programmed cell death. One of the major proteins involved in this process is the tumor suppressor protein, p53, which mediates either cell cycle arrest or induction of apoptosis (19). Cancer cells also adapt survival mechanisms, thereby avoiding apoptosis (20). Two major pathways mediating drug-induced apoptosis have been characterized; one requires the activation of cell surface receptors, whilst the other directly targets mitochondria (21). Bcl-2 is a pro-oncogene protein. One of the most accepted inhibitors of apoptosis is the proto-oncogene Bcl-2 family, and extensive studies have demonstrated that bcl-2 acts as a negative regulator of apoptosis (22).

Doxorubicin is a member of the anthracyclin group that inhibits topoisomerase II, and Docetaxel is one of the microtubul inhibitors. Both antineoplastics are widely used in the therapy of breast cancer, as well as in in vivo and in vitro studies. In this study, the effect of Doxorubicin and Docetaxel in the spheroidal model consisting of the MCF-7 cell line was shown using immunohistochemical techniques. The effect of these two drugs or their combination on apoptosis and the influence of laminin and type IV collagen on metastases and invasion after chemotherapy is discussed.

\section{Materials and methods}

Cell line and cell culture. The human breast cancer cell line, MCF-7, was kindly provided by Dr J.R. Bertino from the Memorial Sloan-Kettering Cancer Center, New York, USA. This tumor cell line is maintained in culture as adherent cells and cultured in RPMI-1640 (Sigma Chemical Co., St Louis, MO) plus $10 \%$ heat inactivated fetal calf serum (FCS) (Sigma), added to $1 \% \mathrm{~L}$ glutamin (Sigma), $1 \%$ non-essential amino acids (Sigma), 10.000 units $/ \mathrm{ml}$ penicillin (Sigma), and $10 \mathrm{mg} /$ $\mathrm{ml}$ streptomycin (Sigma). The cell line was grown in a humidified atmosphere at $37^{\circ} \mathrm{C}$ in $5 \% \mathrm{CO}_{2}$. When the tumor cell lines were used as target cells, they were treated with tyripsin-EDTA (Sigma), washed, and resuspended in complete medium. Dimethylsulfoxide (DMSO) and trypan blue dye were purchased from Sigma (Sigma). Stock solutions of the reagents were prepared in PBS, medium or DMSO as appropriate.

Determination of the cytotoxicity of Doxorubicin and Docetaxel on MCF-7 cells. Target tumor cells were resuspended in medium at $1 \times 10^{5}$ cells $/ \mathrm{ml}$ after verifying cell viability by trypan blue dye exclusion assay. MCF-7 cells were treated with a final concentration of Doxorubicin as 0.01-0.1-0.5-1.0 $\mu \mathrm{g} / \mathrm{ml}$ and Docetaxel as 2.5-5-10-15-20 $\mu \mathrm{g} / \mathrm{ml}$ in 6-well-plates. After 72-h incubation the cells were trypsinized and the cytotoxicity was determined by trypan blue dye exclusion test. To determine $\mathrm{IC}_{50}, 1 / 10$ dilutions were applied. Experiments were performed at least three times and representative data are presented.

Spheroid culture. MCF-7 human breast cancer cells were cultured at $37^{\circ} \mathrm{C}$ in a humidified atmosphere $\left(5 \% \mathrm{CO}_{2}\right.$ in air) in RPMI-1640 medium supplemented with $10 \%$ heat-inactivated fetal bovine serum (FBS) and antibiotics, and passaged weekly. Spheroids were obtained by inoculating $10^{6}$ cells in $10 \mathrm{ml}$ of RPMI-FBS $10 \%$ in Petri dishes on a thin layer of agar (10 ml of a $0.75 \%(w / v)$ solution of agar in RPMI-FBS $10 \%)$. Spheroids (approximately 2000-4000 cells per spheroid) were harvested by gentle repeated transfer with a micropipette of individual spheroids into the wells of a 24-well culture plate. MTS were then individually placed into the wells of a 24-well culture plate containing $1 \mathrm{ml}$ of RPMI-FBS $10 \%$ on a layer of $1 \mathrm{ml}$ of $0.75 \%(w / v)$ agar in the same medium. Every 7 days, $0.5 \mathrm{ml}$ of RPMI medium was gently removed from each well and the wells were then filled with the same amount of fresh medium.

Immunohistochemical staining. Spheroids which were treated with Doxorubicin, Docetaxel and drug combination were gently removed from the surface of the solidified agarose. For immunohistochemical analysis for light microscopic observations, the spheroids were fixed in $4 \%$ paraformaldehyde (Sigma) in phosphate-buffered saline (PBS, pH 7.4) for $24 \mathrm{~h}$ at $4^{\circ} \mathrm{C}$, then washed in PBS. Following fixation the spheroids were dehydrated through graded ethanol $(80,95$ and $100 \%$ sequentially), cleared in xylene, embedded in paraffin, and $5 \mu \mathrm{m}$ coronal sections were cut on microtome (Leica MR 2145). Sections were floated in a sterile bath, collected on poly-L-lysine-coated glass slides and dried at room temperature. For immunohistochemistry, sections were incubated at $60^{\circ} \mathrm{C}$ overnight and then dewaxed in xylene for $30 \mathrm{~min}$. After soaking in a decreasing series of ethanol, sections were washed with distilled water and PBS for $10 \mathrm{~min}$ and then treated with $2 \%$ trypsin in $50 \mathrm{mM}$ Tris buffer $(\mathrm{pH} 7.5)$ at $37^{\circ} \mathrm{C}$ for $15 \mathrm{~min}$ and washed with PBS. Sections were delineated with a Dako pen (Dako, Glostrup, Denmark) and incubated in a solution of $3 \% \mathrm{H}_{2} \mathrm{O}_{2}$ for 15 min to inhibit endogenous peroxidase activity. Then, sections were washed with PBS and incubated with primary antibodies to bcl-2 (1:100 dilution; MS-123, Neomarkers, Fremont, CA), p53 (1:100 dilution; MS-186, Neomarkers), Ki67 (1:100 dilution, RB-081-A1, Neomarkers) monoclonal anti-collagen type IV (1:100 dilution, Dako) and laminin (1:100 dilution, Novocastra, Newcastle, UK). Next, the sections were incubated with biotinylated IgG 


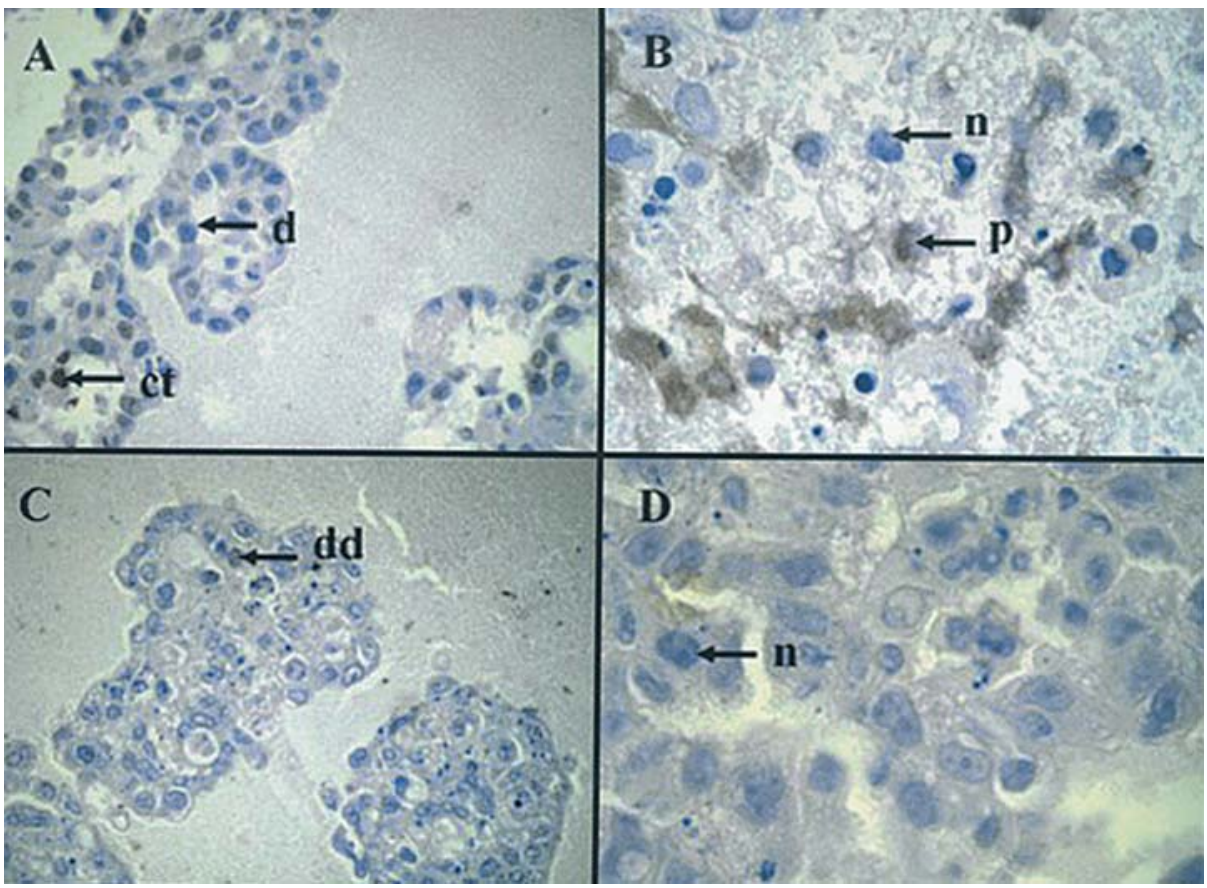

Figure 1. TUNEL method was used for in situ apoptotic cell death staining was done with DAB and counter staining was performed in Mayer's hematoxylin. A, TUNEL positive cells were detected in control (ct) group and microscopic ductus formation (d) of breast is existing on spheroids (x100). B, Positive (p) immunostained and negative (n) immunostained cells on Doxorubicine group (x100). C, Docetaxel/Doxorubicin group (dd) have least Tunel positive cell number (x40). D, All of the cells were negative stained (n) on Docetaxel group (x100).

and then with streptavidin-peroxidase conjugate (HistostainPlus Bulk Kits; Zymed, South San Francisco, CA). Then, the sections were washed with PBS. p53, bcl-2 and Ki67 were incubated with a solution containing 3-amino-9-ethylcarbazole (AEC), and laminin and collagen type IV were incubated with diaminobenzidine (DAB) for 5 min to visualize immunostaining. Finally, sections were counterstained with Mayer's hematoxylin. Control samples were processed in the same manner except that the primary antibodies were omitted.

Detection of apoptotic cell death in situ using the TUNEL method. The in situ apoptosis detection kit (DeadEnd Colorimetric TUNEL system, Promega G7130) was used in order to detect apoptosis. Five $\mu \mathrm{m}$ sections were cut from the paraffin blocks of the samples. The sections were deparaffinized in xylene, rehydrated and incubated with $20-\mu \mathrm{g} / \mathrm{ml}$ proteinase $\mathrm{K}$ for $10 \mathrm{~min}$ and rinsed in distilled water. Endogenous peroxidase activity was inhibited with $3 \%$ hydrogen peroxide. The sections were then incubated with equilibration buffer for 10-15 sec and TdT-enzyme in a humidified atmosphere at $37^{\circ} \mathrm{C}$ for $60 \mathrm{~min}$. They were subsequently put into pre-warmed working strength stop/wash buffer at room temperature for $10 \mathrm{~min}$ and incubated with antistreptavidin-peroxidase for $45 \mathrm{~min}$. Each step was separated by careful washing in PBS. Staining was performed with DAB and counterstaining was performed in Mayer's hematoxylin.

Evaluation of sections. All sections were analyzed under a light microscope (Olympus BX40, Tokyo, Japan). Staining intensity was graded independently by 2 observers blinded to the experimental conditions on the following scale: mild $(+)$, moderate (++) and strong (+++). Approximately 100 TUNEL- positive cells per case were counted using randomly chosen fields. The percentage of apoptotic cells stained brown was determined. Cells in areas with necrosis, poor morphology or in the margins of sections were not analysed.

\section{Results}

Cytotoxic effects of chemotherapy drugs on MCF 7 cells. The doubling time of MCF-7 cells in our culture conditions is found to be $72 \mathrm{~h}$. MCF-7 cells were incubated with final concentrations of Doxorubicin and Docetaxel. Significant growth inhibition was observed in cells incubated with increasing concentrations. $\mathrm{IC}_{50}$ of Doxorubicin is found to be $0.1 \mu \mathrm{g} / \mathrm{ml}$ at $72 \mathrm{~h}$, and $\mathrm{IC}_{50}$ of Docetaxel is found to be $5 \mathrm{ng} / \mathrm{ml}$.

Drug-induced apoptosis in human breast cancer cell spheroids. To understand the cell death mechanism on MCF-7, spheroids were used to determine differences in their sensitivity in the molecular process triggered by Doxorubicin, Docetaxel and drug combination. While TUNEL-positive cells were detected in the control (Fig. 1A), Doxorubicin (Fig. 1B), and Docetaxel/Doxorubicin groups (Fig. 1C), there were no TUNEL-positive cells in the Docetaxel group (Fig. 1D). In the control group, there were more TUNEL-positive cells than in the Doxorubicin- and Docetaxel/Doxorubicin-treated cell lines.

Expression of p53, bcl-2 and Ki67. After immunohistochemical evaluation of sections, positive immunoreactivity of p53 was detected in control (Fig. 2A), Doxorubicin- (Fig. 2B) and Docetaxel/Doxorubicin- (Fig. 2C) treated cell lines. The expression of p53 was moderate (++) in control cell lines and 


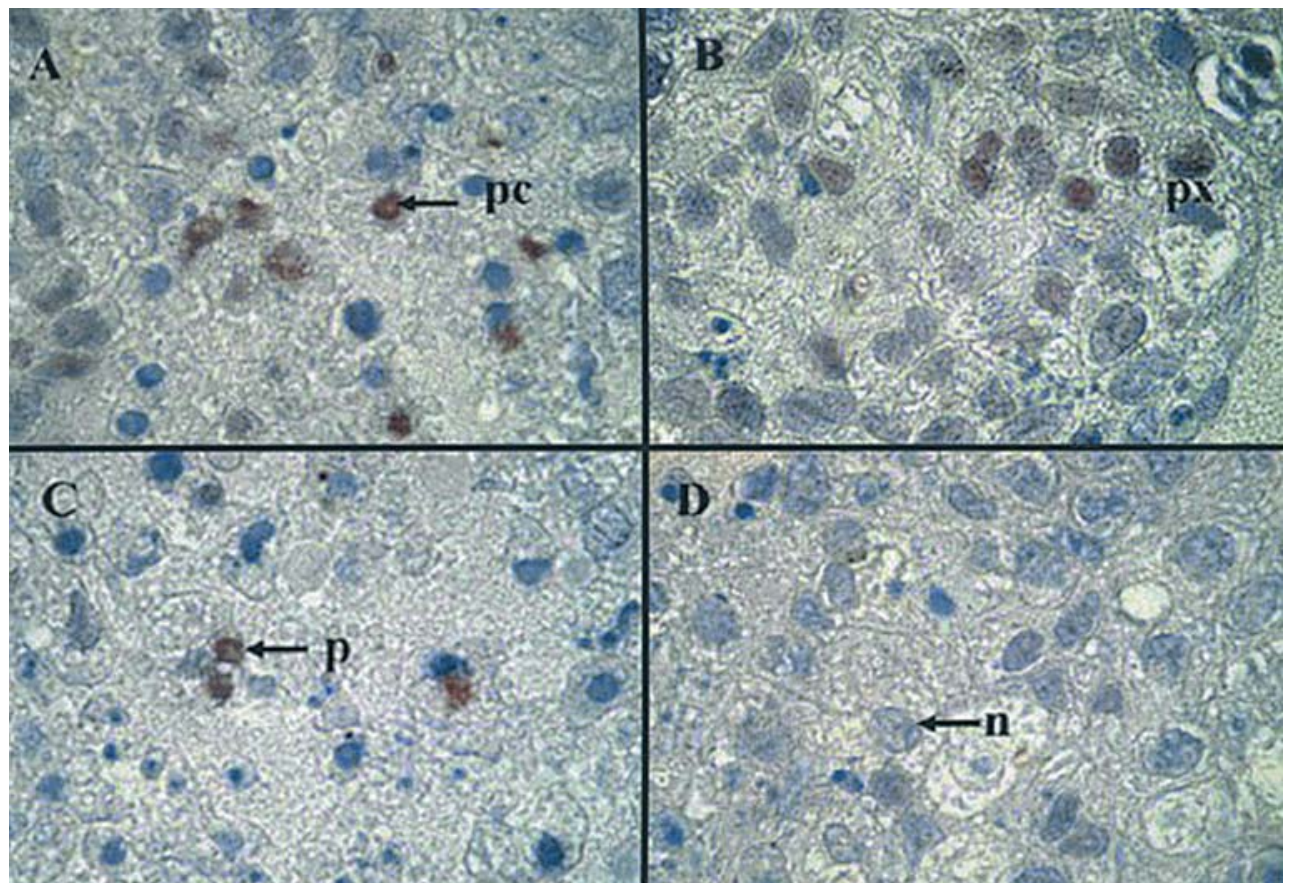

Figure 2. The tumor suppressor protein, p53, was examined using immunohistochemistry. Staining was performed with AEC and counterstaining was performed in Mayer's hematoxylin. A, Positive immunoreactivity of p53 was detected in the control (pc) group (x100). B, Doxorubicine group (px) (x100). C, Docetaxel/Doxorubicine-treated cells (p). D, There was negative immunoreactivity (n) on Docetaxel-treated cells. The expression of p53 was moderate $(++)$ in cell lines from control and after treatment with Doxorubicine, mild $(+)$ expression was detected after treatment with Docetaxel/Doxorubicinetreated cells $(\mathrm{x} 100)$.

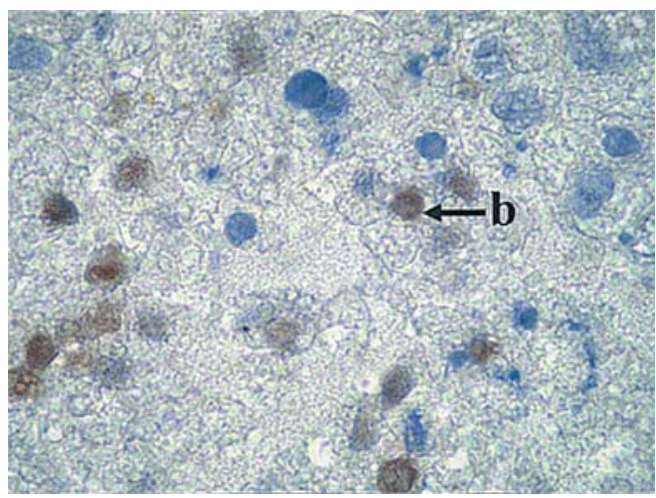

Figure 3. After immunohistochemical evaluation of sections, mild (+) expression of bcl-2 was only detected in the control group (b). Negative expression of bcl was detected on Doxorubicin, Docetaxel and drug combination-treated groups (x100).

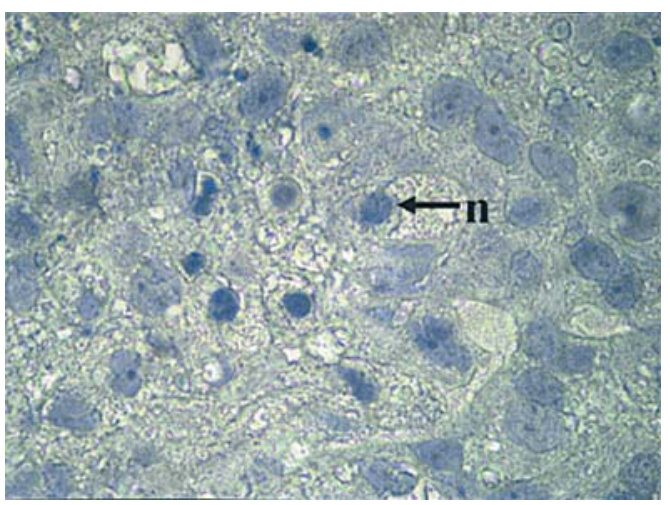

Figure 4. Ki67 immunoreactivity was not shown in any of the groups (n) on immunohistochemical sections (x100).

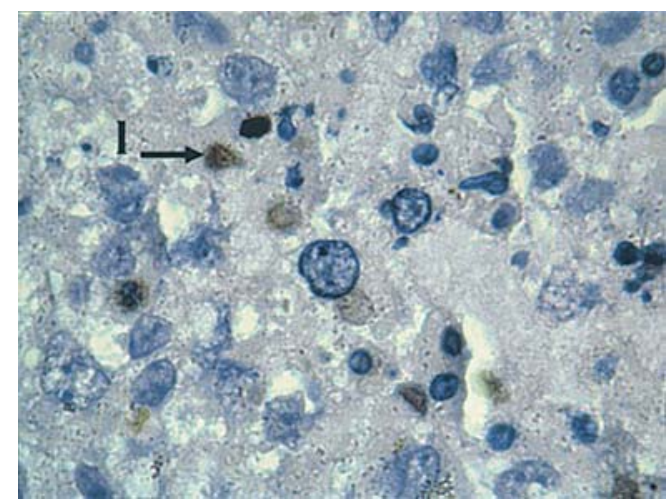

Figure 5. Positive immunoreactivity of Laminin was demonsrated on the control group (1). Negative expression was detected on Doxorubicin, Docetaxel and drug combination groups (x100).

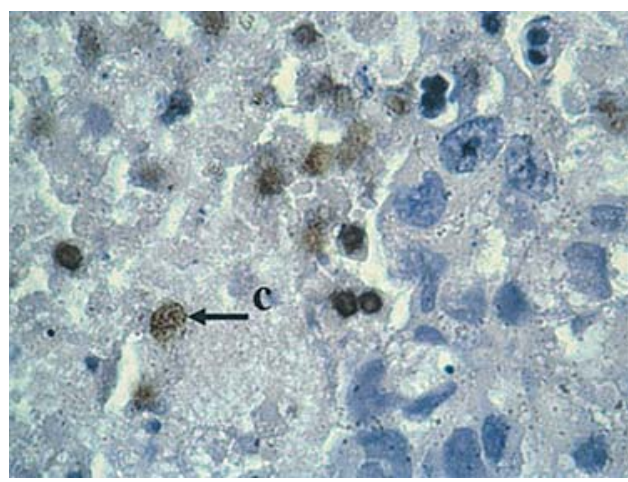

Figure 6. Positive immunoreactivity type IV collagen were demonsrated on the control group (c) although type IV collagen immunoreactivity was not shown in the other drug treatment groups on immunohistochemical sections (x100). 
Table I. Expression of p53, bcl-2 genes and Ki67, and detection of apoptotic cell death in situ using the TUNEL method.

p53 Bcl-2 Ki67 TUNEL

\begin{tabular}{lcccc}
\hline Control & ++ & ++ & - & +++ \\
Doxorubicine & ++ & - & - & ++ \\
Docetaxel/Doxorubicine & + & - & - & + \\
Docetaxel & - & - & - & - \\
\hline
\end{tabular}

after treatment with Doxorubicin, whereas mild (+) expression was detected after treatment with Docetaxel/Doxorubicin (Table I). In contrast, mild (+) expression of bcl-2 was only detected in the control group (Fig. 3). Neither p53 (Fig. 2D) nor bcl-2 immunoreactivity was detected in Docetaxel-treated cell lines. Ki67 immunoreactivity was not shown in any of the groups on immunohistochemical sections (Fig. 4).

Dispersion of laminin and type IV collagen and response to chemotherapy. Positive immunoreactivity of laminin (Fig. 5) and type IV collagen (Fig. 6) were demonsrated in the control group. However, negative expression was detected in the Doxorubicin, Docetaxel and drug combination groups. Neither laminin nor type IV collagen immunoreactivity was detected in Doxorubicin-, Docetaxel- and drug combination-treated spheroids.

\section{Discussion}

Human breast carcinomas are biologically heterogeneous, and their clinical course may vary from one which is indolent to one which rapidly progresses (23). The studies performed with spheroids present the distribution of cells in the spheroid either at the resting stage or in proliferation, the expression of antigens, the gradient of $\mathrm{pH}$ and oxygen and also the probable ways of penetrating the growth factors in in vivo tumors and spheroidal models. The comparative studies performed with monolayer cell cultures have shown that all the known cytotoxic agents used on the monolayer cell line are less effective on developing cancer cells than in spheroidal models (24). In a previous study, we demonstrated that Doxorubicin causes cell death with apoptosis and Docetaxel with necrosis in the MCF-7 monolayer cell line (25). In this study, we aimed to determine which pathway was controlling the apoptosis in these cell lines after treatment in an MCF-7 tumor spheroid model. More TUNEL-positive cells were detected in the control group than other groups, and also there were positive immunoreactivities of p53 and bcl-2 in the control group. This finding shows that apoptosis was controlling the expression of both p53 and bcl-2 and using cell death and survive signalling pathway together in control group. TUNELpositive cells and p53 immunoreactivity were detected in Doxorubicin- and Docetaxel/Doxorubicin-treatment groups, but immunoreactivity of p53 was found more in the Doxorubicin group. However, it seems that in Doxorubicin and Docetaxel/ Doxorubicin groups, apoptosis was controlled by the expression of p53 because of the detection of the intense immunoreactivity of p53 but no bcl-2 expression, although there were more TUNEL-positive cells and higher expression of p53 in the Doxorubicin group, confirming that this treatment could give positive results of controlling cell death via apoptosis. We have confirmed that there were no TUNEL-positive cells or expression of p53 and bcl-2 in the Docetaxel group. Therefore, treatment with this drug in the cell line was not controlled using the apoptotic pathway.

Bcl-2 was the first protein to be clearly associated with apoptosis inhibition. Several independent signal transduction pathways leading to cell death converge in a final common effect or mechanism in which bcl-2 acts as a dominant repressor (26). This protein localizes to the mitochondrial membrane, nuclear envelope and endoplasmic reticulum (27). The imbalance between cell survival and apoptosis could be crucial in the progression of breast cancer, allowing the accumulation of genetic alterations (28), and tumor suppressor, $\mathrm{p} 53$, functions as a transcriptional factor that regulates the cell cycle and apoptosis (29). In this study, decreased expression of p53 and the number of TUNEL-positive cells were observed after treatment with the combination of Doxorubicin and Docetaxel. When using this drug combination there was more less cell death with apoptosis, compared to Doxorubicin alone. From this result, we conclude that to combine Doxorubicin with another drug to induce apoptosis might be of great benefit to clinical cancer therapy.

$\mathrm{Ki} 67$ is a nuclear protein that is expressed throughout the cell cycle. The absence of Ki67 protein is a marker for nonproliferating cells that have entered G0 phase and, therefore, provides a means of monitoring whether cell cycle exit might contribute to growth arrest (30). In unshown data for the Ki67 immunohistostaining with MCF-7 breast multicellular tumor spheroids, we did not observe positive immunoreactivity of Ki67 in either group. Therefore, we conclude that the absence of the Ki67 protein in MCF-7 breast multicellular tumor spheroids is related to the cells in $\mathrm{G} 0$ or $\mathrm{S}$ phase.

In carcinomas, the cellular organization is dramatically changed and the stroma is extensively modified. The basement membrane is penetrated in a process of degradation and/or decreased synthesis, and direct contact between tumor cells and the surrounding stroma coincides with neovascularization, inflammatory cell influx and extensive remodeling of extracellular matrix (31). Malignant tumors consist of both neoplastic cells and non-neoplastic cellular elements, including fibroblasts, endothelial cells, lymphocytes and macrophages, surrounded by an extracellular matrix (ECM) (32). This study was intended to examine the influence of the ECM components that may act as natural barriers to tumor cell invasion on MCF-7 spheroids after chemotherapy. Interactions between neoplastic cells and the surrounding microenvironment are crucial to each step of tumorigenesis. The extracellular matrix also consists of the interstitium and the basement membrane. A crucial step for invasion and metastasis is the destruction of biological barriers such as the basement membrane, and this requires activation of proteolytic enzymes $(33,34)$. ECM proteins, which include type IV collagen and laminin, affect the in vitro growth, morphology, survival, and differentiation of normal and malignant cells via their interactions with integrins (16). This in vitro study, researching the relationship of ECM-invasion-metastasis, used a spheroid 
model with cellular interactions compatible to the in vivo tumor model.

Multicellular spheroids are an in vitro model of micrometastasis. Cellular interaction with fibronectin, laminin and collagen provides a possible mechanism by which cancer cells adhere, invade and metastasize, and inhibition of cellular adhesion to the matrix reduced the invasive potential of breast cancer cell lines (35). The affinity of MCF-7 cells for type-IV collagen was greater than for fibronectin, suggesting that type-IV collagen contributes to the higher rate of adhesion of MCF-7 cells to the subendothelial ECM. MCF-7 cells appeared to adhere more efficiently to exposed subendothelial ECM when they were associated with multicellular aggregates containing platelets and trapped in a fibrin thrombus (36). The results of this study show that positive immunoreactivities of laminin and type IV collagen were detected in the control group although these immunoreactivities were negative after chemotherapy. This suggests that chemotherapy might be effective via preventing expression of type IV collagen and laminin in metastatic biology. There was no type IV collagen and laminin immunoreactivity in either drug group. In conclusion, the results from the present study demonstrate that apoptosis is detected in all groups except the Docetaxeltreated group, but apoptosis particularly controlled the p53 signalling pathway after chemotherapy, and Doxorubicin treatment gave positive results of controlling cell death via apoptosis. In further studies, each of these two drugs will investigate preponderants to each other using different laboratory techniques.

\section{References}

1. Parkin DM, Laara E and Muir CS: Estimates of the world-wide frequency of sixteen major cancers in 1980. Int J Cancer 41: 184-197, 1988 .

2. Quinn M and Allen E: Changes in incidence of and mortality from breast cancer in England and Wales since introduction of screening. United Kingdom Association of Cancer Registries. BMJ 311: 1391-1395, 1995.

3. Santini MT and Rainaldi G: Three-dimensional spheroid model in tumor biology (Review). Pathobiology 67: 148-157, 1999.

4. Becker JL, Prewett TL, Spaulding GF and Goodwin TJ: Threedimentional growth and differentiation of ovarian tumor cell line in high aspect rotating-wall vessel: Morphologic and embryologic considerations. J Cell Biochem 51: 283-289, 1993.

5. Streuli CH and Bissel MJ: Mammary epithelial cells, extracellular matrix, and gene expression. Cancer Treat Res 53: 365-381, 1991.

6. Boudreau N and Bissell MJ: Extracellular matrix signaling: integration of form and function in normal and malignant cells, Curr Opin Cell Biol 10: 640-646, 1998.

7. Colognato $\mathrm{H}$ and Yurchenco P: Form and function: the laminin family of heterotrimers. Dev Dyn 218: 213-234, 2000.

8. Terranova VP, Liotta LA, Russo RG and Martin GR: Role of laminin in the attachment and metastasis of murine tumor cells. Cancer Res 47: 2265-2269, 1982.

9. Chung AE, Jaffe R, Freeman I, Vergnes J, Braguiski J, Carlin B: Properties of a basement membrane-related glycoprotein synthesized in culture by a mouse embryonal carcinoma-derived cell line. Cell 16: 277-281, 1979.

10. Terranova VP, Rohrbach DH and Martin GR: Role of laminin in the attachment of PAM 212 (epithelial) cells to basement memebrane collagen. Cell 22: 719-728, 1980.

11. Cotran RS, Kumar V and Collins T: Robbins Pathological Basis of Disease. Saunders, Philadelphia, 1999.

12. Terranova VP, Rao CN, Kalebic T, Margulies IM and Liotta LA: Laminin receptor on human breast carcinoma cells. Cell Biol 80: 444-448, 1983.

13. Chintala SK, Gokaslan ZL, Go Y, Sawaya R, Nicolson GL and Rao JS: Role of extracellular matrix proteins in regulation of human glioma cell invasion in vitro. Clin Exp Metastasis 14: 358-366, 1996.
14. Fearon ER: Cancer progression. Curr Biol 9: R873-R875, 1999.

15. Hanahan D and Weinberg RA: The hallmarks of cancer. Cell 100: 57-70, 2000.

16. Casey RC, Burleson KM, Skubitz KM, Pambuccian SE, Oegema TR Jr, Ruff LE and Skubitz AP: Beta 1-integrins regulate the formation and adhesion of ovarian carcinoma multicellular spheroids. Am J Pathol 159: 2071-2080, 2001.

17. Kleinman HK, Klebe RJ and Martin GR: Role of collagenous matrices in the adhesion and growth of cells. J Cell Biol 88: 473$485,1981$.

18. Hay ED: Cell Biology of Extracellular Matrix. Hay ED (ed). Plenum, London, pp1-39, 1981.

19. Slee EA, O'Connor DJ and Lu X: To die or not to die: how does p53 decide? Oncogene 23: 2809-2818, 2004.

20. Mercurio AM, Bachelder RE, Chung J, O'Connor KL, Rabinovitz I, Shaw LM and Tani T: Integrin laminin receptors and breast carcinoma progression. J Mammary Gland Biol Neoplasia 6: 299-309, 2001.

21. Green DR: Apoptotic pathways: the roads to ruin. Cell 94: 695-698, 1998.

22. Kluck RM, Bossy-Wetzel E, Green DR and Newmeyer DD: The release of cytochrome $\mathrm{c}$ from mitochondria: a primary site for Bcl-2 regulation of apoptosis. Science 275: 1132-1136, 1997.

23. Kang HS, Youn YK, Oh SK, Choe KJ and Noh DY: Flow cytometric analysis of primary tumors and their corresponding metastatic nodes in breast cancer. Breast Cancer Res Treat 63: 81-87, 2000.

24. Frankel A, Man S, Elliott P, Adams J and Kerbel RS: Lack of multicellular drug resistance observed in human ovarian and prostate carcinoma treated with the proteasome inhibitor PS-341. Clin Cancer Res 6: 3719-3728, 2000.

25. Oktem G, Karabulut B, Selvi N, Sezgin C, Sanli UA, Uslu R, Yurtseven ME and Omay SB: Differential effects of doxorubicin and docetaxel on nitric oxide production and inducible nitric oxide synthase expression in MCF-7 human breast cancer cells. Oncol Res 14: 381-386, 2004.

26. Kroemer G: The proto-oncogene $\mathrm{Bcl}-2$ and its role in regulating apoptosis. Nat Med 3: 614-620, 1997.

27. Krajewski S, Tanaka S, Takayama S, Schibler MJ, Fenton W and Reed JC: Investigation of the subcellular distribution of the bcl-2 oncoprotein: residence in the nuclear envelope, endoplasmic reticulum, and outer mitochondrial membranes. Cancer Res 53: 4701-4714, 1993.

28. Cherbonnel-Lasserre C, Gauny S and Kronenberg A: Suppression of apoptosis by $\mathrm{Bcl}-2$ or $\mathrm{Bcl}-\mathrm{xL}$ promotes susceptibility to mutagenesis. Oncogene 13: 1489-1497, 1996.

29. Laux MT, Aregullin M, Berry JP, Flanders JA and Rodriguez E: Identification of a p53-dependent pathway in the induction of apoptosis of human breast cancer cells by the natural product, resveratrol. J Altern Complement Med 10: 235-239, 2004.

30. Van Dierendonck JH, Keijzer R, van de Velde CJ and Cornelisse CJ: Nuclear distribution of the Ki-67 antigen during the cell cycle: comparison with growth fraction in human breast cancer cells. Cancer Res 49: 2999-3006, 1989.

31. Ronnov-Jessen L, Petersen OW and Bissell MJ: Cellular changes involved in conversion of normal to malignant breast: importance of the stromal reaction. Physiol Rev 76: 69-125, 1996.

32. Hagemann T, Robinson SC, Schulz M, Trumper L, Balkwill FR and Binder $\mathrm{C}$ : Enhanced invasiveness of breast cancer cell lines upon co-cultivation with macrophages is due to TNFalpha dependent up-regulation of matrix metalloproteases. Carcinogenesis 25: 1543-1549, 2004.

33. Coussens LM and Werb Z: Matrix metalloproteinases and the development of cancer. Chem Biol 3: 895-904, 1996.

34. Liotta LA and Stetler-Stevenson WG: Tumor invasion and metastasis: an imbalance of positive and negative regulation. Cancer Res 51: 5054-5059, 1991.

35. Gui GP, Puddefoot JR, Vinson GP, Wells CA and Carpenter R: In vitro regulation of human breast cancer cell adhesion and invasion via integrin receptors to the extracellular matrix. $\mathrm{Br} \mathrm{J}$ Surg 82: 1192-1196, 1995.

36. Abecassis J, Millon-Collard R, Klein-Soyer C, Nicora F, Fricker JP, Beretz A, Eber M, Muller D and Cazenave JP: Adhesion of human breast cancer cell line MCF-7 to human vascular endothelial cells in culture. Enhancement by activated platelets. Int J Cancer 40: 525-531, 1987. 